\title{
Educação Ambiental:
}

\author{
Prática e Percepções de Estudantes
} de $8^{\text {a }}$ Série do Ensino Fundamental Acerca de Problemas Ambientais Locais

\author{
Tania Renata Prochnow ${ }^{1}$ \\ Cely Mariza Vargas da Silveira²
}

\begin{abstract}
Resumo
Este artigo foi estruturado a partir de pesquisa realizada com estudantes de $8^{\underline{a}}$ série do Ensino Fundamental objetivando analisar sua percepção e práticas relacionadas aos problemas ambientais do lugar onde residem, estimular sua consciência ambiental e avaliar sua compreensão sobre aos problemas ambientais. Trata-se de estudo de caráter descritivo com abordagem qualitativa e quantitativa, com 40 estudantes com idades entre 13 e 17 anos. Como instrumentos de coleta de dados foram utilizados questionários aplicados aos alunos, bem como suas observações ambientais complementadas pelo registro em imagens fotográficas. A análise teórica contextualiza sinteticamente aspectos da questão ambiental atual, estabelecendo sua relação com o processo civilizatório contemporâneo, bem como com problemas sociais, históricos, culturais e legislação ambiental brasileira; aborda mecanismos que envolvem a percepção ambiental enfatizando o Desenvolvimento Sustentável e a Educação Ambiental. Realizou-se análise discursiva dos relatos dos estudantes procurando estabelecer interconexões entre seus processos perceptivos. Os participantes demonstraram clareza na percepção dos problemas ambientais a sua volta, por meio de relatos e imagens fotográficas captadas do ambiente em observação. Revelaram ter atitudes em relação à preservação do ambiente e preocupação quanto aos impactos ambientais devidos à ação humana, responsabilizando as pessoas por esses impactos, bem como pelas mudanças necessárias para alcançar a sustentabilidade.
\end{abstract}

Palavras-chave: Percepção ambiental. Educação ambiental. Problemas ambientais.

${ }^{1}$ Doutora em Ciências pelo Centro de Ecologia da UFRGS. Professora do Programa de Pós-Graduação em Ensino de Ciências e de Matemática - PPGECIM e dos cursos de Química (Licenciatura e Química Industrial) e de Engenharia Ambiental da Universidade Luterana do Brasil - Ulbra.taniapro@gmail.com

2 Aluna do curso de Especialização (lato sensu) em Novas Tecnologias e Metodologias de Ensino de Ciências da Natureza da Universidade Luterana do Brasil; professora da rede municipal de ensino de Sapucaia do Sul. cmvsilveira@yahoo.com.br 


\title{
ENVIRONMENTAL EDUCATION: \\ Perceptions and Practices of 8Th Series \\ of Fundamental Teaching About Local Environmental Problems
}

\begin{abstract}
This article was structured as a research carried out with eighth grade students of Elementary School, aiming to analyze their perception and practices related to the environmental problems of the place where they reside, to stimulate their environmental awareness and to evaluate their understanding about environmental problems. This is a descriptive study with a qualitative and quantitative approach, with 40 students aged 13 to 17 years. As data collection instruments were used questionnaires applied to the students, as well as their environmental observations complemented by the registration in photographic images. Theoretical analysis contextualizes synthetically aspects of the current environmental issue, establishing its relation with the contemporary civilization process, as well as with social, historical, cultural and brazilian environmental laws; approaches mechanisms that involve environmental perception emphasizing Sustainable Development and Environmental Education. A discursive analysis of the students' reports was carried out, trying to establish interconnections between their perceptive processes. Participants demonstrated clarity in the perception of the environmental problems around them, through their reports and photographic images captured from the environment under observation. They have demonstrated that they have attitudes towards the preservation of the environment and concern about the environmental impacts due to human action, making people responsible for them, as well as the changes needed to achieve sustainability.
\end{abstract}

Keywords: Environmental perception. Environmental Education. Environmental problems.

Recebido em: 24/4/2017

Aceito em: 7/8/2017 
A escola é um espaço social privilegiado para a produção de atividades sobre a temática ambiental, visto que as características dos escolares no processo ensino-aprendizagem remetem à formação crítica da sua própria relação com o meio ou da sociedade em que estão inseridos. É imprescindível que a educação estimule os estudantes a observar e a perceber o meio ambiente criticamente e, desta forma, promova condições para que se sensibilizem com os problemas ambientais do nosso tempo visando ao desenvolvimento de sua consciência, sua socialização e aquisição de valores ambientais embasados na conservação e preservação da natureza. Estes fatores são pressupostos estreitamente relacionados à formação de cidadãos responsáveis e com perspectivas de contribuição para um futuro sustentável.

Compreende-se que a relação homem-ambiente-sociedade decorre de vários fatores intrínsecos ao ser humano que são carregados de signos e representações resultantes das interações emocionais, do meio social familiar e cultural em que ele está inserido. Segundo Fuchs (2008), o homem transforma-se por meio da educação e a Educação Ambiental (EA) torna-se indispensável ao longo da vida do indivíduo para garantir uma relação de equilíbrio com o meio ambiente e, dessa forma, fazer com que se sinta parte dele. Sendo assim, a visão de problemas ambientais locais pode despertar nos estudantes interrogações que os levem a refletir sobre as diferentes questões deste assunto, tais como: Qual é sua dinâmica relacional no espaço em que vivem? Suas ações consideram a preservação do meio ambiente e contribuem para a sustentabilidade? Que atitudes efetivas podem ser tomadas para preservar o meio em que vivem?

Conhecer a percepção dos estudantes em relação aos problemas ambientais permitirá abordagens sobre o tema objetivando fortalecer e resgatar valores que sinalizem possíveis mudanças de comportamento, tendo em vista as perspectivas negativas das questões ambientais do mundo contemporâneo.

\section{A Questão Ambiental e a Educação Ambiental: breves considerações}

O atual estágio de desenvolvimento da sociedade humana resultou em uma evidente crise de problemas ambientais em âmbito planetário. Por meio de uma visão antropocêntrica e utilitarista do mundo, o homem tem promovido a degeneração do meio ambiente e conduzindo o planeta a um iminente caos ambiental. 
Notadamente, a questão ambiental na forma como se instaurou nos dias atuais, tem suas origens no século 18 a partir da Revolução Industrial. Relaciona-se, portanto, a um processo histórico de um modelo econômico de produção capitalista e de padrões tecnológicos, numa lógica racional de acúmulo de riquezas e estímulo ao consumo (LEFF, 2006).

De acordo com Boff (2012), na atualidade atingimos parâmetros de agressão ambiental semelhante a uma guerra total em que atacamos a Terra em todos os ecossistemas, atingindo tanto seus componentes bióticos como abióticos, expressando uma concepção de Terra como uma fonte inesgotável na qual os seus recursos podem ser explorados de forma ilimitada. A noção de um planeta praticamente sem limites desencadeou alterações no espaço global e, entre outros fatos, promoveu o crescimento desordenado das cidades, e o aumento crescente da população humana determinou a massificação do consumo e a degradação ambiental (DIAS, 2004). Como consequência, surgiram inúmeros problemas sociais marcados pelas desigualdades entre os países e estratos societários, caracterizando uma dura realidade socioambiental.

No Brasil, desde a década de 70 do século passado já ocorriam ações direcionadas ao debate dos problemas ambientais do país. Segundo Carvalho (2008), nessa mesma década as intensas mudanças estruturais e sociais que aconteceram no Brasil propiciaram condições à formação das entidades ambientalistas no decênio seguinte. Sob este aspecto, Viola e Leis (1997 apud PELICIONI, 2005) destacam que na década de 80 o ambientalismo brasileiro expandiu-se para diversos setores da sociedade, como nas organizações não governamentais (ONGs), nas universidades, nos meios de comunicação e nas agências não especificamente ambientais. Há que se considerar também, que as Conferências Internacionais sobre Meio Ambiente e EA exerceram influências no Brasil, de forma que se instituíram políticas e ações governamentais neste campo (CARVALHO, 2008).

O marco oficial da institucionalização da EA no Brasil ocorreu por meio da Lei Federal de $n^{\circ} 6.938$ de 31 de agosto de 1981, que constituiu a Política Nacional do Meio Ambiente (PNMA), na qual se estabeleceu a necessidade de inclusão da EA em todos os níveis de ensino e inclusive na comunidade como 
forma de empoderamento dos cidadãos para a ação em defesa do meio ambiente (BRASIL, 1981). Em 1987 O Conselho Federal de Educação, órgão de políticas educacionais do Ministério de Educação e Cultura, emitiu o Parecer $n^{\circ}$ 226/87, que considera imprescindível a inserção da EA nos conteúdos a serem desenvolvidos pelos currículos das escolas de Educação Básica, observando a necessidade da "formação de uma consciência pública voltada ou dirigida para a preservação da qualidade ambiental" e propõe que sejam realizadas ações neste sentido a "partir da escola, levando a população a posicionamento em relação a fenômenos ou circunstâncias do ambiente" (DIAS, 2008, p. 44).

A Constituição Federal - CF de 1988 (BRASIL, 1988) reconhece o direito constitucional de todos os cidadãos brasileiros à EA atribuindo ao Estado o dever de "promover a Educação Ambiental em todos os níveis de ensino e a conscientização pública para a preservação do meio ambiente".

O Ministério da Educação promoveu um workshop no Rio de Janeiro, em 1992, cujo resultado foi a "Carta Brasileira para Educação Ambiental”, que reconhecia a EA como meio para atingir a sustentabilidade, que é uma condição essencial à sobrevivência e melhoria da qualidade da vida humana no planeta Terra (BRASIL, 2014). Em 1994 foi criado o Programa Nacional de Educação Ambiental que, segundo Dias (2008), tem por objetivo "instrumentalizar politicamente o processo de EA no Brasil”. Na sua versão mais atualizada (2005) o texto do Programa menciona "que suas ações destinam-se a assegurar, no âmbito educativo, a interação e a integração equilibradas das múltiplas dimensões da sustentabilidade ambiental - ecológica, social, ética, cultural, econômica, espacial e política - ao desenvolvimento do país, buscando o envolvimento e a participação social na proteção, recuperação e melhoria das condições ambientais e de qualidade de vida" (BRASIL, 2014).

A Lei no 9.394 (BRASIL, 1996), que instituiu as Diretrizes e Bases da Educação Nacional, faz sucintas referências à EA, onde encontramos:

Art. 32- O ensino fundamental obrigatório, [...], terá por objetivo a formação básica do cidadão, mediante: 
II - a compreensão do ambiente natural e social, do sistema político, da tecnologia, das artes e dos valores em que se fundamenta a sociedade (Lei 9394/96, 1996, atualizada 2013).

Conforme Barbieri (2010), a LDB não constitui disposições ou cita de forma expressa a EA, uma vez que estes aspectos da Lei sempre estiveram presentes nos currículos escolares e em todos os níveis de ensino e não são suficientes para formar uma consciência socioambiental com mudanças de ações e capacidade de agir ambientalmente conforme os objetivos da EA.

No ano de 1997 os Parâmetros Curriculares Nacionais - PCN - foram aprovados pelo Conselho Nacional de Educação (órgão do MEC), cujo texto teve como subsídio a LDB. Os PCN recomendam que os currículos escolares incluam temas relevantes do cotidiano dos alunos, tais como: ética, saúde, meio ambiente, orientação sexual, pluralidade cultural, trabalho e consumo (BRASIL, 1997). Considerando a temática meio ambiente/EA os currículos escolares do Ensino Fundamental, segundo os PCN, têm a função de colaborar para o desenvolvimento de uma cidadania ambiental, formando sujeitos conscientes e com preparo para decidir e agir diante das questões socioambientais, comprometidos com o bem comum de forma local e global (BRASIL, 1998).

De acordo com Loureiro (2012), um ponto elogiável dos PCN reside no fato de inserirem a temática ambiental nos currículos escolares articulados às áreas do conhecimento sem ser tratada como uma disciplina, posto que as ações do cotidiano localmente remetem a possibilidades de construção coletiva de forma a diminuir e/ou superar os processos de degradação ambiental, com resgate da qualidade de vida e uma ética ecológica.

A EA no Brasil tem como referencial a Política Nacional de Educação Ambiental (Pnea), que foi instituída pela Lei $\mathrm{n}^{\circ} 9.795$ que, em seu artigo $1^{\circ}$, define a Educação Ambiental como "processos por meio dos quais o indivíduo e a coletividade constroem valores sociais, conhecimentos e habilidades, atitudes e competências voltadas para conservação do meio ambiente, bem de uso comum do povo, essencial à sadia qualidade de vida e sua sustentabilidade" e que a "Educação Ambiental é componente essencial e permanente da educação nacional, devendo estar presente, de forma articulada, em todos os níveis e 
modalidades do processo educativo, em caráter formal e não formal" (BRASIL, 1999). A Pnea prevê um roteiro para a prática da educação ambiental e sua regulamentação ocorreu pelo Decreto $n^{\circ}$ 4.281/02 (BRASIL, 2002) que indica os Ministérios da Educação (MEC) e do Meio Ambiente (MMA) como órgãos gestores da Política Nacional de Educação Ambiental.

Em 2012 foram aprovadas pelo Conselho Nacional de Educação as Diretrizes Curriculares Nacionais para a Educação Ambiental (DCNEA), no contexto da educação formal (BRASIL, 2014). Segundo Adams (2012), em um artigo que faz uma análise crítica sobre as DCNEA, os objetivos da EA apresentados no documento são amplos e sinalizam para uma educação crítica em relação ao ambiente, inter-relacionando aspectos socioambientais e cidadania.

Considerando os aspectos históricos da EA no Brasil, percebe-se que em nosso país ocorreram inúmeros avanços neste campo do conhecimento desde os anos 80 do século passado. Nesse sentido, entretanto, caminhamos a passos lentos comprovados pela demora na concretização de políticas públicas pertinentes à EA bem como no seu cumprimento efetivo com abrangência não apenas das instituições de ensino, mas também da comunidade brasileira em geral.

\section{Percepção Ambiental}

O contato que os indivíduos têm com o mundo (meio ambiente) ocorre por meio das sensações captadas pelos órgãos dos sentidos. Este elo entre o homem e a natureza chama-se de percepção ambiental.

Segundo Del Rio (1991, 1996 apud FIGUEIREDO, 2011), a percepção ambiental é consequência do processo de interação do indivíduo com o meio ambiente que ocorre mediante mecanismos perceptivos (guiados por estímulos externos como a visão, olfato, audição, etc.) e mecanismos cognitivos (relacionados à inteligência do indivíduo). Dessa forma, é possível afirmar que a percepção ambiental ocorre por influência mútua entre o indivíduo e o meio no qual ele está inserido.

Okamoto (2002) afirma que o cérebro seleciona as informações recebidas, e dessa forma considera que: 
Temos a sensação do ambiente pelos estímulos desse meio, sem ter consciência disso. Pela mente seletiva, diante do bombardeio de estímulos, são selecionados os aspectos de interesse ou que tenham chamado atenção, e só aí é que ocorre a consciência (pensamento, sentimento), resultando em uma resposta que conduz a um comportamento (p. 27).

Na concepção de Naime e Garcia (2004), cada ser humano percebe, reage e responde diferentemente diante das ações sobre o meio. As respostas ou manifestações são resultado das percepções, dos processos cognitivos, avaliações e expectativas que cada indivíduo tem da realidade.

Para Teramussi (2008) os processos perceptivos não são idênticos para um mesmo objeto; assumem aspectos diversos conforme o contexto sociocultural no qual a pessoa se insere, visto que o modo de perceber o mundo está vinculado à cultura, determinando assim que cada grupo social ou indivíduo elabore decodificações próprias de acordo com suas vivências.

Cada sujeito sente, avalia, cria e conduz de modo particular suas ações ou comportamentos, segundo sua percepção, sua subjetividade e o entendimento do meio ambiente ao seu redor. Daí decorre que a percepção inadequada da realidade promove uma relação inadequada homem x natureza, de forma desagregadora, comprometendo tanto a estabilidade ambiental quanto a social (COIMBRA, 2004). Dessa maneira os estudos de percepção ambiental podem levar à sensibilização e conscientização dos sujeitos envolvidos na pesquisa com relação às atitudes e comportamentos no contexto em que vivem. Estes aspectos podem remeter a mudanças dos aspectos negativos da interação dos indivíduos com a natureza. Neste estudo, portanto, a expressão “percepção ambiental” tem o sentido de conscientização do ambiente.

\section{Sustentabilidade x Desenvolvimento Sustentável: dilemas conceituais e a interface da EA}

Analisando a EA relacionada ao Desenvolvimento Sustentável (DS), Barbieri e Silva (2011) mencionam que muitas definições, objetivos, metodologias e outros fatores destas questões já foram até hoje arrolados em inúmeras 
conferências sobre meio ambiente e em diversas partes do mundo. Para os autores as Conferências da Biosfera (em Paris, 1968) e de Estocolmo (na Suécia, 1972) são os marcos referenciais para as temáticas que envolvem o DS e a EA, respectivamente.

Diferentes autores, entre os quais Sauvé (1997), Lima (2003), Jacobi (2003, 2004, 2005), Leff (2004), Dias (2008) e Boff (2012), têm produzido textos dando ênfase a estes temas aqui considerados. A análise dos escritos esclarece-nos o grau de complexidade que envolve estas discussões, visto que há inúmeros fatores relacionados aos aspectos econômicos, sociais, culturais, políticos e éticos, tanto de ordem local quanto global, imprescindíveis de serem considerados.

De acordo com as concepções de Sorrentino (2005), implicitamente o DS traz a ideia do uso da natureza como recurso, sendo tratada a fim de atender às necessidades do modelo econômico capitalista globalizante, cujo padrão de desenvolvimento é monopolista e consequentemente produz iniquidades sociais. Nessa perspectiva, vamos nos reportar às considerações de Dias (2008) sobre EA quando ele comenta que “... o objetivo central da EA é a promoção do desenvolvimento sustentável" (p. 119), este último sendo concebido por meio de três dimensões inter-relacionadas que constituem a sua base: o desenvolvimento econômico, o social e o equilíbrio ambiental, o que nos remete a pensar na existência de uma perfeita harmonia entre as dimensões consideradas básicas para o desenvolvimento sustentável em nossos dias, discordando do pensamento de Sorrentino. A realidade do mundo atual nos induz a pensar que estas dimensões e o desenvolvimento sustentável encontram-se em posições opostas, pois os problemas sociais disseminam-se pelo mundo enquanto que a degradação e o descaso ambiental são crescentes.

Com relação à definição de sustentabilidade, Boff (2012) menciona ser o conjunto de processos relacionados a dar continuidade à vitalidade da Terra $\mathrm{e}$ da vida das espécies nela existentes, tendo como fatores essenciais a manutenção da natureza preservada e conservada simultaneamente ao desenvolvimento humano, de forma a atender às necessidades presentes e das futuras gerações. 
O autor argumenta ainda que cidadãos socialmente participantes e conscientes em relação à natureza e ao seu modo particular de recuperação são indicativos para uma sociedade sustentável.

Díaz (2002) refere-se à escola como formadora de sujeitos capazes de intervir na realidade global e complexa, entretanto faz-se necessário que a educação se alinhe a este novo paradigma da complexidade. "Temos de promover uma educação que responda precisamente a esta realidade global e complexa, e que dê uma resposta adequada a seus problemas, entre eles o da crise ambiental" (p. 35). Segundo o autor, a educação pode ser dita sustentável quando priorizar a formação de um pensamento crítico diante dos problemas ambientais, resultando em atitudes e comportamentos com base em valores humanísticos.

De acordo com Jacobi (2003), a sustentabilidade adquire em nossa época um papel crucial no que se refere ao desenvolvimento da humanidade e seus possíveis encaminhamentos, dada a complexidade dos impactos ambientais resultantes da ação antrópica no ambiente. Os problemas socioambientais suscitam a participação da sociedade no gerenciamento dos recursos e nas decisões pautadas na "sustentabilidade ecológica e equidade social", com mudanças substanciais das relações no binômio sociedade/natureza e até mesmo do processo civilizatório. $\mathrm{O}$ autor refere que

[...] a ideia de sustentabilidade implica na prevalência da premissa de que é preciso definir uma limitação nas possibilidades de crescimento e um conjunto de iniciativas que levem em conta a existência de interlocutores e participantes sociais relevantes e ativos através de práticas educativas e de um processo de diálogo informado, o que reforça um sentimento de co-responsabilização e de constituição de valores éticos (JACOBI, 2004, p. 31).

Diante de todas estas questões, constata-se que são muitas as vertentes e as possibilidades de pensar e discutir os temas propostos.

O objetivo deste estudo foi analisar a percepção e as práticas destes estudantes relacionadas aos problemas ambientais dos lugares em que residem. Considerou-se estimular a consciência ambiental dos estudantes, bem como avaliar a sua compreensão sobre os problemas ambientais e quais suas atitudes 
em relação ao meio ambiente. É imprescindível que a educação estimule os estudantes a observarem e a perceberem o meio ambiente criticamente e, dessa forma, promova condições para que se sensibilizem com os problemas ambientais do nosso tempo. Tais aspectos suscitam o desenvolvimento de sua consciência, sua socialização e aquisição de valores ambientais embasados na conservação e preservação da natureza. Acredita-se que estes fatores são pressupostos estreitamente relacionados à formação de cidadãos responsáveis e com perspectivas de contribuição para um futuro sustentável.

\section{Metodologia}

Desenvolveu-se uma pesquisa com estudantes de $8^{\text {a }}$ série do Ensino Fundamental de uma Escola Estadual de Ensino Médio, localizada no município de Sapucaia do Sul/RS. Trata-se de um estudo de caráter descritivo com abordagem qualitativa e quantitativa dos dados, com a participação de 40 estudantes com idades entre 13 e 17 anos. A Escola surgiu como um projeto de ser uma escola modelo, bem equipada, com objetivo de atender às leis de ensino vigentes no país naquela época (SILVEIRA, 2005).

O município de Sapucaia do Sul, no qual a escola se localiza, faz parte da Região Metropolitana de Porto Alegre e tem, conforme Censo 2010 do IBGE, uma população de 130.957 habitantes (destes, apenas 488 residem na zona rural e o restante na zona urbana). Em Sapucaia do Sul $98 \%$ dos domicílios possuem água tratada e o manancial para captação da água bruta é o Rio dos Sinos. O esgoto cloacal é parcialmente tratado e, na maior parte da cidade, é utilizado o tratamento por fossa séptica com ou sem sumidouro (GONÇALVES, 2013). Conforme dados disponibilizados pela Secretaria do Meio Ambiente de Sapucaia do Sul (2014), há um cronograma para a coleta dos resíduos domiciliares urbanos. Quanto à EA, a Secretaria do Meio Ambiente da cidade também disponibiliza materiais de divulgação (folders) referentes à poda de árvores e posse de animais domésticos. O Centro Municipal de Educação Ambiental (Cemea) de Sapucaia do Sul desenvolve atividades na área de EA mediante a realização de oficinas 
temáticas, palestras sobre diferentes temas ambientais e recreio dirigido com jogos educativos sobre meio ambiente. Além disso, nas visitas das escolas ao Cemea os alunos realizam trilhas educativas.

\section{Procedimentos Metodológicos}

A metodologia utilizada neste estudo ocorreu de acordo com as três etapas descritas a seguir: levantamento de dados para dar subsídios à pesquisa; elaboração do Instrumento de Coleta de Dados - ICD - (questionário) que foi usado na pesquisa com os estudantes e na terceira etapa fez-se a sistematização do trabalho, com a análise dos dados coletados e síntese de textos.

Realizou-se uma pesquisa de caráter descritivo com abordagem qualitativa e quantitativa com relação à análise dos dados. Segundo Gil (2002), os estudos de natureza descritiva têm como foco conhecer as características de determinadas populações ou fenômenos. Uma de suas particularidades é utilizar técnicas padronizadas de coleta de dados; para o autor, o questionário é um instrumento caracterizado pela interrogação direta das pessoas pela qual se obtém respostas acerca do que fazem, sabem e creem.

De acordo com Moresi (2003), a abordagem quantitativa em uma pesquisa refere-se a todos os seus aspectos quantificáveis. Tal fato indica que as informações podem ser traduzidas em números para classificá-las e analisá-las por intermédio de recursos e técnicas estatísticas. Com relação à pesquisa qualitativa, há que se considerar a dinamicidade entre a realidade e os sujeitos pesquisados, lembrando que a subjetividade dos indivíduos não pode ser traduzida em números para ser analisada (MORESI, 2003). Nesse sentido, Minayo e Gomes (2013) mencionam que a pesquisa qualitativa ocupa-se com os significados, as motivações, os anseios, as crenças e os valores das pessoas e referem ainda:

Esse conjunto de fenômenos é entendido aqui como parte da realidade social, pois o ser humano se distingue não só por agir, mas por pensar sobre o que faz e por interpretar suas ações dentro e a partir da realidade vivida e partilhada com seus semelhantes (p. 21). 
Desta maneira, é possível destacar que a percepção sobre o meio ambiente referida pelos estudantes pesquisados revela suas concepções e suas ideias sobre o assunto e, portanto, não são mensuráveis, mas passíveis de interpretação dos seus significados.

\section{Coleta dos Dados}

Os dados desta pesquisa foram coletados utilizando um questionário composto por 10 questões (abertas e fechadas, com justificativa da resposta) abordando a percepção ambiental dos estudantes. Anteriormente à entrega do ICD fez-se uma sucinta explanação sobre os objetivos da pesquisa. No momento da entrega do questionário procedeu-se à leitura de cada uma das questões para eliminar as dúvidas dos alunos no momento de completá-lo. O questionário foi levado para casa e devolvido na aula seguinte.

Além da entrega do ICD, os alunos foram orientados a fotografar o ambiente de acordo com o assunto das questões propostas no questionário. As fotografias foram enviadas por correio eletrônico (e-mail) e armazenadas pela pesquisadora para compor o banco de dados da pesquisa.

\section{Análise dos Dados}

Para análise dos resultados da pesquisa, com relação ao aspecto quantitativo, foi utilizado o programa Microsoft Excel 2007® para criar uma base de dados com posterior tratamento estatístico por meio de gráficos. Além disso, também foram elaboradas tabelas com a síntese tanto dos dados quantitativos quanto qualitativos. A análise descritiva dos dados foi realizada utilizando o cálculo das distribuições de frequências e percentuais.

Para a análise dos componentes qualitativos da pesquisa, além da produção das tabelas citadas anteriormente, procedeu-se à estruturação das questões do questionário em temáticas diferentes visando a avaliar a percepção dos estu- 
dantes sobre o ambiente em que vivem. A análise das respostas dos estudantes foi realizada tentando deduzir o sentido dado por eles aos aspectos ambientais nas questões que estavam sendo avaliadas.

\section{Resultados e Discussão}

Dos 40 estudantes da amostra inicial, apenas 36 alunos constituíram a amostra final de participantes da pesquisa. Quatro alunos da amostragem não responderam às questões.

Dos 36 estudantes participantes deste estudo, 18 são do sexo feminino e 18 do sexo masculino. Tal fato caracteriza uma amostra homogênea em relação ao gênero. As idades dos estudantes pesquisados variaram entre 13 e 14 anos (31 alunos) e 15 e 17 anos (5 alunos). Os alunos pesquisados moram em diferentes bairros da cidade de Sapucaia do Sul. Verificou-se uma concentração maior dos estudantes (14) pesquisados no mesmo bairro de localização da escola deste estudo.

\section{Percepção Ambiental dos Estudantes}

\section{Temática Água - Arroio}

As questões relacionadas a esta temática referem-se a um arroio específico, o arroio José Joaquim, que atravessa vários bairros de Sapucaia do Sul, incluindo alguns nos quais residem os estudantes participantes do estudo.

Para a Questão 1: “Existe acúmulo de resíduos sólidos no arroio jogado pelas pessoas?", 32\% (13) dos alunos responderam afirmativamente quanto à presença de resíduos sólidos dentro do arroio, enquanto que um percentual menor, $20 \%$ (8), responderam negativamente para a mesma questão; 38\% (15) afirmaram não existir arroio no seu bairro de moradia e 10\% (4) não responderam (Figura 1). 
Uma possível justificativa para as afirmações discordantes dos estudantes quanto à presença ou não de resíduos sólidos no arroio pode estar relacionada ao local (bairro) em que realizaram sua observação ou a população de determinados bairros pode estar mais consciente quanto ao descarte adequado destes materiais.

Figura 1 - Acúmulo de resíduos sólidos no arroio jogado pelas pessoas do bairro

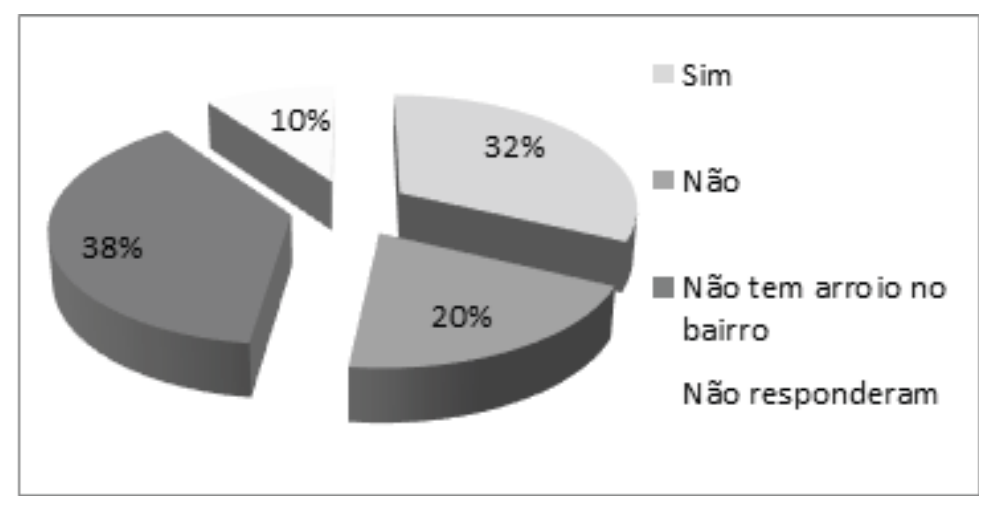

Fonte: A pesquisa.

Quanto à Questão 2: "Existe vegetação nas margens do arroio? Descreva as margens do mesmo.”, apenas $10 \%$ (2) dos estudantes da amostra cujo bairro tem arroio responderam que não há vegetação em suas margens, portanto um percentual significativamente maior, 90\% (19), declararam existir vegetação nas margens do arroio. Dos alunos participantes da pesquisa, 15 residem em bairros em que não há arroio.

Para demonstrar estas constatações seguem-se algumas descrições dos estudantes:

- Estão sujas e meio amareladas, dependendo do lugar.

- As margens são de pedra e cheio de vegetação, mato.

- Tem pedras com limos e em cima tem árvores, grama e capim. 
Por outro lado, as respostas selecionadas a seguir demonstram outra forma de percepção do ambiente que alguns estudantes evidenciaram ter, conforme nosso entendimento, mais restrita em relação às citadas anteriormente:

- Um matagal, cheio de lixos, galhos.

- Estão precárias por causa do acúmulo de lixo.

Entre os que afirmaram não existir vegetação nas margens do arroio, um deles referiu que "estão limpas, sem matos". Entre as possibilidades do significado deste relato podemos referir que o estudante utiliza "limpas, sem matos" para designar a vegetação rasteira às margens do arroio.

Para a Questão 3: "A água do arroio tem odor desagradável? Descreva as características da água.”, 81\% (17) dos estudantes pesquisados, residentes próximos a arroios, referiram que a água tem odor desagradável, enquanto que um percentual relativamente menor, 19\% (4), não confirmou ter a água esta mesma característica.

Considerando a descrição da água do arroio, a seguir estão alguns dos relatos dos estudantes.

- A água é bem marrom, sem peixes e tem muita poluição nela.

- Água suja, sem vida, péssimo odor, é canalizado.

- Água escura, com muita sujeira e com pouca água, algumas partes não tem água.

- Água escura, com lixo e às vezes animais mortos.

- Está marrom, não tem peixes e não tem entulhos ou lixo, apenas algumas folhas.

Como já mencionado anteriormente, é possível referir, também, neste caso, as diferentes formas de percepção dos estudantes para um mesmo aspecto observado. Além disso, podemos associar que as suas observações foram realizadas em locais distintos ao longo do arroio, visto que há aspectos contraditórios nos seus relatos, quando referiram "não tem entulhos ou lixo", "tem muita poluição nela” ou “com lixo”. 


\section{Temática $\mathrm{Ar}$}

Por meio do primeiro questionamento quanto a esta temática, a Questão 4: "O ar do seu bairro tem alguma alteração que possa ser percebida pelo cheiro? Se afirmativo justifique a resposta.", indicou que 40\% (16) dos estudantes responderam positivamente para alterações de odor ar do seu bairro e, contrariamente, 50\% (20) deles relataram não ocorrer tal característica no seu local de residência. Outros 10\% (4) não responderam à questão (Figura 2).

Figura 2 - Percepção dos estudantes quanto a alterações de odor do ar do bairro

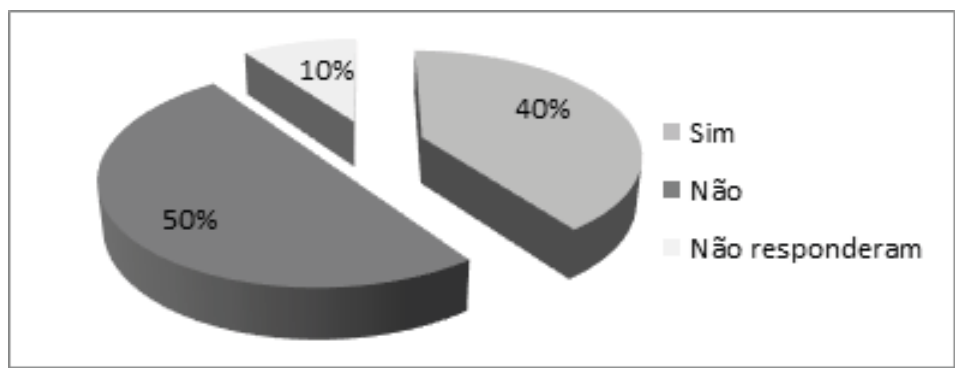

Fonte: A pesquisa.

Observe-se que estas divergências nas respostas afirmativas ou negativas, para alteração de odor no bairro, podem estar relacionadas ao fato de que os estudantes pesquisados residem em diferentes bairros da cidade de Sapucaia do Sul. Tal fato pode ser comprovado pelas justificativas relatadas por eles para essas alterações, como se observa a seguir:

- O mau cheiro do ar é de indústrias e oficinas.

- O mau cheiro é porque vizinhos queimam galhos, folhas secas.

- Às vezes, tem uma mata ao lado de minha casa onde queimam lixo, daí dá cheiro desagradável.

- O mau cheiro é das queimadas porque os vizinhos queimam lixo à volta do arroio.

- O mau cheiro é do arroio.

- É um ar bem comum onde eu moro. 
Pelas justificativas dos alunos percebe-se que há segmentos de economia (indústrias e oficinas) citados por eles como possíveis causadores das alterações de odor no seu bairro e que podem não estar presentes em outros. A presença de "queimadas", porém, foi um aspecto importante a destacar dos relatos da maior parte dos estudantes, que afirmou que o ar do seu bairro apresenta alterações de odor, tal como já descrito. Acredita-se que são hábitos que revelam a falta de EA de parte da população destes bairros da cidade.

Sabe-se que na queima ocorre formação de compostos orgânicos voláteis e material particulado, produzindo assim uma série de poluentes do ar causadores de doenças, além de outras implicações para a atmosfera. Além dos aspectos supracitados, a legislação brasileira, representada pela Política Nacional dos Resíduos Sólidos, proíbe a queima de resíduos sólidos de qualquer natureza a céu aberto (BRASIL, 2010).

Quanto ao relato do estudante que mencionou ser "bem comum o ar do seu bairro" nos traz a ideia de que para ele isto significa ar sem alterações ou até mesmo ar bom para respirar.

\section{Temática Flora}

A abordagem sobre a temática Flora iniciou-se com a Questão 5: "As árvores do seu bairro têm galhos secos, folhas amareladas ou estão sem casca? Caso afirmativo justifique.”. A análise dos dados revelou que apenas 20\% (8) dos estudantes pesquisados afirmaram que a flora do bairro em que residem apresenta alterações. Por outro lado, a maior parte deles, $70 \%$ (28), mencionou não existirem alterações na vegetação do seu bairro; $10 \%$ (4) deles não responderam à questão (Figura 3). 
Figura 3 - Percepção dos estudantes sobre alterações na flora do bairro

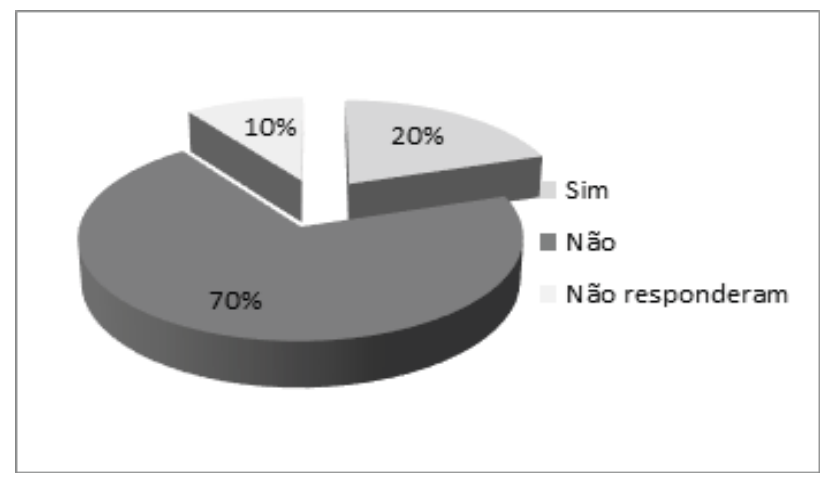

Fonte: A pesquisa.

Entre as justificativas dos estudantes para as alterações da vegetação percebidas por eles destacam-se as que seguem:

- Por causa da poluição do ar.

- Algumas árvores em terreno baldio aqui são secas pela queima de galhos, folhas e entulhos.

- Porque tem muita gente que escreve nas árvores, não sei para que, elas também sofrem.

Em um dos relatos o estudante evidencia a relação entre causa e efeito quando refere que a "poluição é a causa" da alteração da flora do seu bairro. Tal fato mostra que, na percepção dele, há um prejuízo ambiental visível na vegetação cuja origem está na alteração do ar.

Na percepção de diversos estudantes "as queimadas" justificam as alterações da flora do seu bairro. Tal fato confirma nossas descrições anteriores, nas quais os estudantes também as citam como explicação das alterações de odor do ar bairro.

Segundo a Secretaria do Meio Ambiente de Sapucaia do Sul, a poda de árvores somente pode ser feita em casos especiais e mediante licença deste órgão, atendendo à Lei Municipal 3.175/2009; caso ocorra poda de árvores, a 
prefeitura disponibiliza orientações aos munícipes quanto ao local para onde devem conduzir esta matéria verde que será destinada à compostagem. Quanto a este último quesito mencionado, a compostagem da massa verde atende às exigências do Plano Municipal Integrado de Resíduos Sólidos em consonância com os aspectos preconizados pela PNRS (BRASIL, 2010).

Outro estudante demonstra atribuir vida ao ambiente quando refere que "pessoas escrevem em árvores, fazendo-as sofrer". Neste caso, entendemos que ele transfere uma dimensão vital, o sofrimento, a um aspecto da natureza que podemos concluir ser uma relação de aproximação e de inserção ambiental por parte dele.

Entre os estudantes que negaram alterações na vegetação do bairro destaca-se a explicação dada por um deles: "Não, porque todos do bairro cuidam das suas árvores"; os moradores de certos bairros da cidade demonstram ter concepções ambientais que os aproximam de um coletivo mais educado ambientalmente quando comparado a outros.

Diante do exposto é pertinente mencionar as declarações de Mellazo (2005), quando o autor refere que o ser humano deve compreender o espaço urbano como integrante da natureza, primando pela conservação do ambiente e pelo abandono da forma de tratamento leviano que tem a ele dispensado. A cidade, como "organismo vivo", depende dos múltiplos processos e relações que nela ocorrem para manutenção do seu equilíbrio ou desequilíbrio.

\section{Temática Fauna}

A Questão 6: "No seu bairro há animais da fauna nativa?" inicia a investigação sobre a percepção dos alunos em relação à fauna. Mais da metade, $55 \%$ (22), dos estudantes mencionaram a presença de animais da fauna nativa no bairro em que residem, enquanto que um percentual menor deles, 35\% (14), negou a presença desses animais no bairro de sua residência e $10 \%$ (4) não responderam à questão (Figura 4). 
A Questão 7: "No seu bairro há animais da fauna sinantrópica? Cite quais.”, revelou que um número significativo dos estudantes, $87 \%$ (35) da amostra pesquisada referiu existirem animais da fauna sinantrópica no seu bairro de moradia. Contrariamente, apenas 3\% (1) da amostra negou a existência deles, e $10 \%$ (4) dos alunos não responderam (Figura 4).

Figura 4 - Percepção dos estudantes quanto à presença de fauna nativa e sinantrópica no bairro

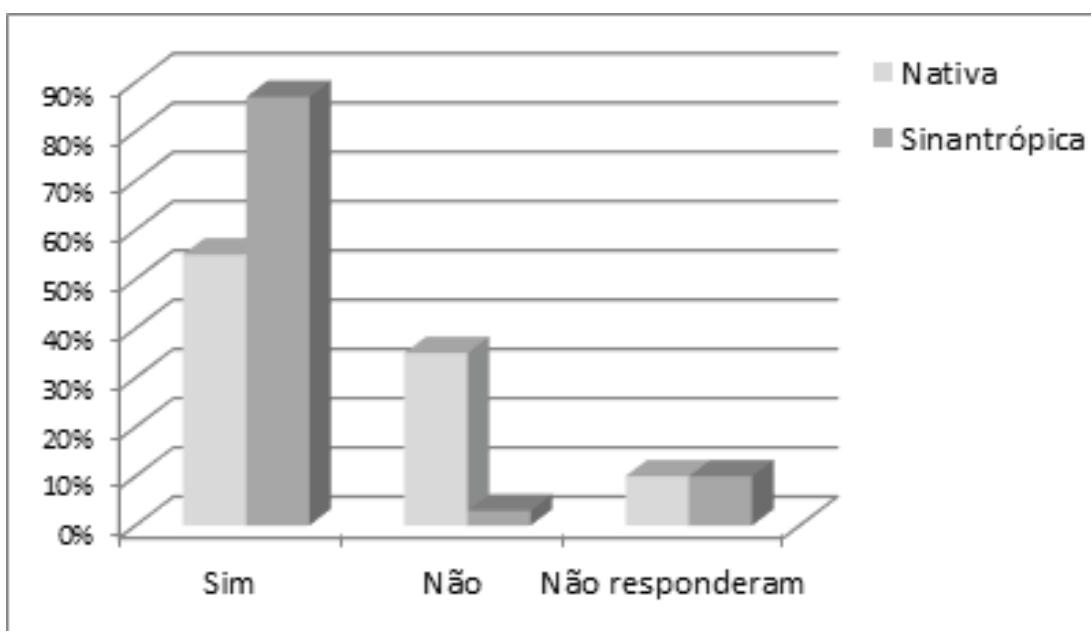

Fonte: A pesquisa.

Um dos estudantes fez o relato a seguir para justificar sua resposta afirmativa quanto à fauna nativa:

- Talvez tenha alguns destes animais na Sociedade [...] aqui na Rua [...].

Este local Sociedade, referido pelo estudante, é uma região do bairro de localização da escola estudada que apresenta uma área verde com árvores diversas. Sabe-se que em áreas com estas características possivelmente há a presença de fauna. Tal fato provavelmente direcionou o estudante a associá-la com a existência de animais nativos. Entende-se que, com esse relato ele demonstra um aspecto pertinente ao conhecimento adquirido anteriormente, associando sua percepção ambiental a aspectos cognitivos resultantes de saberes, desenvolvidos 
na escola. Neste caso, entende-se que a percepção ambiental demonstrada pelo estudante alinha-se às declarações de Del Rio (1991, 1996 apud FIGUEIREDO, 2011), em que o autor refere que este processo resulta de mecanismos guiados não apenas pelos órgãos dos sentidos humanos, mas também por aqueles oriundos das mediações cognoscitivas do indivíduo de forma tal que ambos atuam integradamente em nossos meios perceptivos. Segundo Okamoto (2002), posteriormente a estes processos de percepção advém a consciência, que no caso do estudante revela-se pela linguagem escrita externada, da qual sequencialmente deriva um determinado comportamento como resposta.

Entre os animais sinantrópicos mais citados pelos estudantes temos: pombas, baratas, ratos e pardais com 32, 29, 22 e 9 citações, respectivamente. Percebe-se, a partir desses dados, que a maioria dos estudantes declarou existirem pombas, ratos e baratas em seu bairro de residência.

Entre as citações dos estudantes destacamos as que seguem:

- Tem pombas nos telhados.

- Tem pombas e muitos ratos.

Estes fatos percebidos pelos estudantes confirmam o processo migratório da fauna para as regiões urbanas, cujas causas estão relacionadas a processos econômicos (desmatamentos para diversos fins) e sociais (expansão das cidades para áreas verdes, incremento das taxas populacionais) que promovem alterações no espaço natural, fazendo com que os animais procurem outros locais adaptativos a sua sobrevivência.

A análise da Questão 8: "No seu bairro ou rua há animais domésticos?”, indica que todos os estudantes confirmaram existirem esses animais no seu bairro: $30 \%$ (12) deles admitiram que os animais estavam sempre soltos na rua, enquanto que os demais declararam que eles às vezes estão na rua, 47\% (19), ou nos pátios das casas, $13 \%$ (5). Observa-se que 10\% (4) não responderam ao questionamento (Figura 5). 
Figura 5 - Percepção dos estudantes quanto à presença de fauna doméstica no bairro

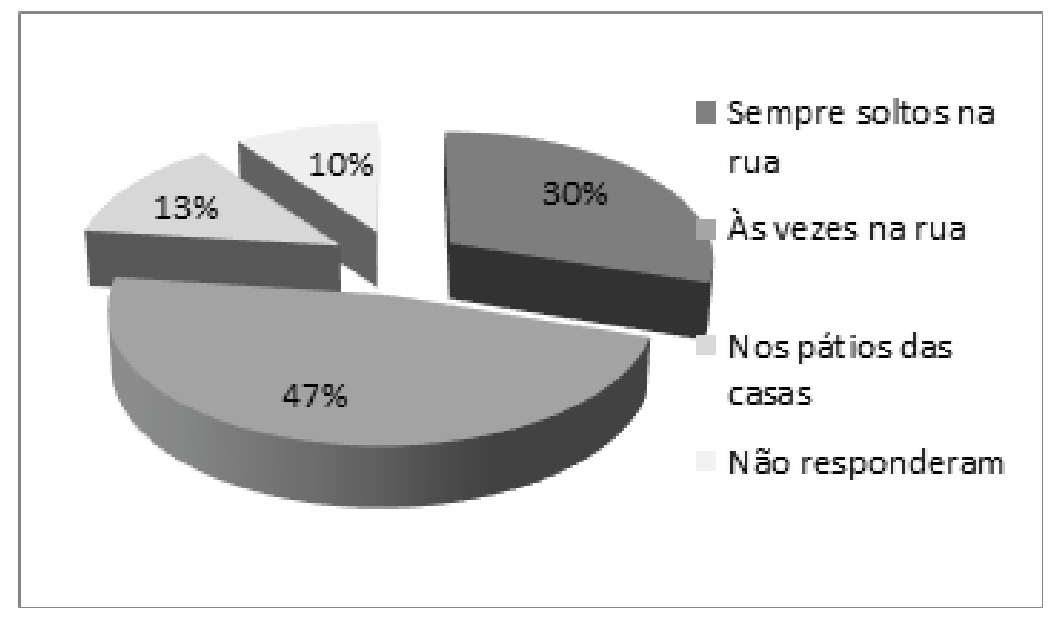

Fonte: A pesquisa.

Por meio destes dados é possível referir que parte da população dos bairros nos quais residem os estudantes demonstra não ter cuidados adequados com os animais que convivem em suas casas. A presença destes animais na rua acarreta inúmeros problemas sociais, como o aumento de sua população, a disseminação de doenças entre eles e, além disso, sabe-se que estes animais são vetores de zoonoses para os humanos. Conforme mencionamos anteriormente, no âmbito da EA a Secretaria do Meio Ambiente da cidade de Sapucaia do Sul desenvolveu um folder que incentiva as pessoas a cuidarem dos seus animais domésticos.

A Figura 6 refere-se a uma seleção de imagens fotográficas captadas pelos estudantes que demonstram a presença de animais domésticos em seus bairros. 
Figura 6 - Animais domésticos na rua

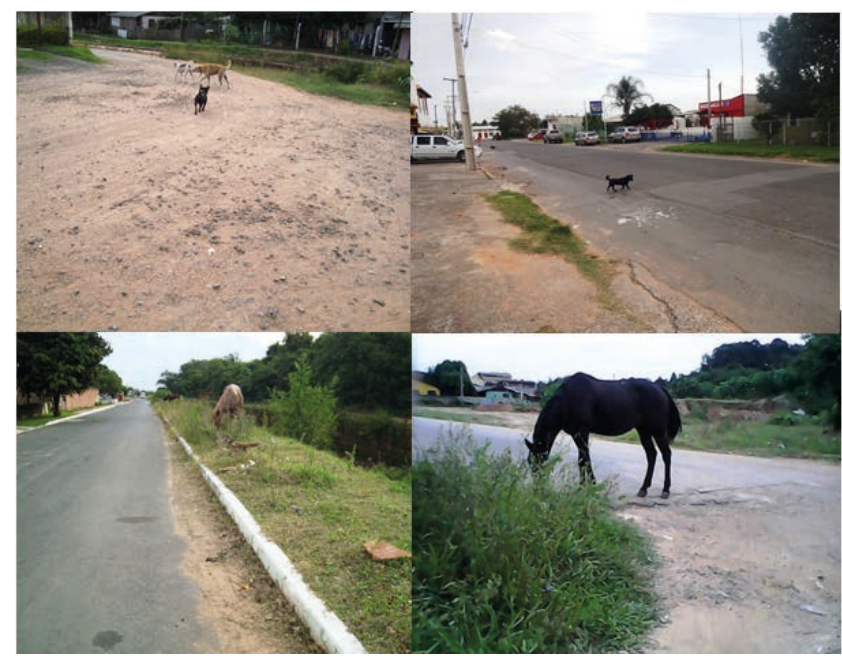

Fonte: Arquivo do autor.

Para a Questão 9: "Você observa a presença de ratos elou baratas na sua rua ou bairro?", apenas $12 \%$ (5) dos estudantes afirmaram não haver ratos e/ou baratas no bairro em que residem, enquanto que $78 \%$ (31) deles reconhece que às vezes observam estes animais na sua rua ou bairro. Outros $10 \%$ (4) não responderam à questão (Figura 7).

Figura 7 - Percepção dos estudantes quanto à presença de ratos e/ou baratas

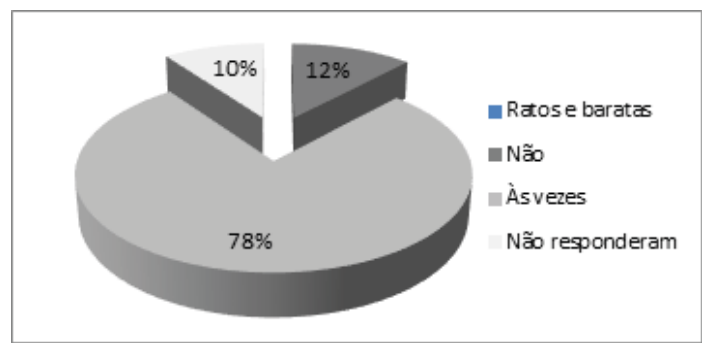

Fonte: Dados da pesquisa. 
Estes dados assemelham-se àqueles obtidos em uma das questões anteriores, em que os estudantes referiram como fauna sinantrópica a presença de ratos e baratas em seus bairros de residência.

\section{Temática Resíduos Sólidos}

Pela análise das respostas à Questão 10: “Existem resíduos sólidos acumulados nas ruas ou em terrenos baldios em seu bairro? Quais os tipos de resíduos?", constata-se que $60 \%$ (24) dos estudantes mencionaram a presença de resíduos sólidos dispostos inadequadamente em seu bairro e 30\% (12) deles asseguraram que isto não ocorre onde residem. Outros 10\% (4) não responderam à questão (Figura 8).

Figura 8 - Percepção dos estudantes sobre o descarte inadequado de resíduos sólidos no bairro

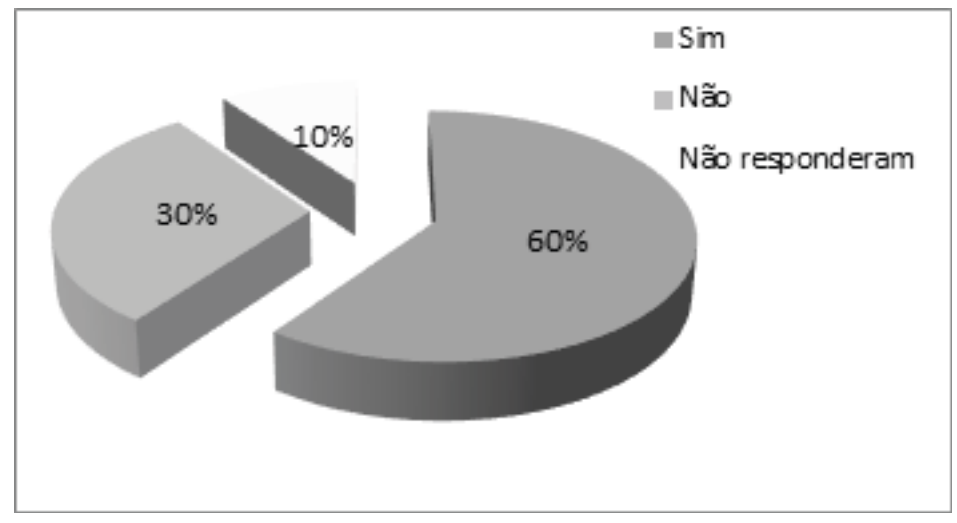

Fonte: A pesquisa.

Quando questionados sobre os tipos de resíduos encontrados a maior parte deles declarou "garrafas PET, restos de construção, pneus, papel", mas também citaram "móveis velhos, restos de alimentos, sacolas plásticas e animais mortos”. Destacam-se a seguir algumas das declarações dos estudantes sobre os resíduos sólidos em seu bairro: 
- Sim. Restos de construções, galhos e folhas caídas, até móveis velhos as pessoas despacham em terrenos baldios.

- Há pneus, restos de casas destruídas, animais mortos, papéis e pet.

- Nunca vi lixo no meu bairro em terreno baldio porque todos os terrenos ou são limpos ou são cercados.

- Existe terreno baldio no meu bairro, mas não tem lixo, tem plantações.

Conforme já discutimos anteriormente, tais declarações divergentes podem estar relacionadas às distintas formas de percepção do ambiente pelos estudantes, bem como a sua procedência de diferentes bairros da cidade, em que determinadas populações demonstram ter maior percepção de cuidado com o ambiente. Observa-se que em Sapucaia do Sul há a coleta regular de resíduos sólidos domiciliares três vezes por semana para a maioria dos bairros. A cidade conta com um aterro sanitário para deposição final, portanto os achados dos estudantes confirmam a deseducação para com o ambiente que a população de certos locais evidencia ter.

A Figura 9 destaca uma seleção de imagens fotográficas captadas pelos estudantes que comprovam os aspectos elencados neste item do estudo. 
Figura 9 - Deposição inadequada de resíduos sólidos

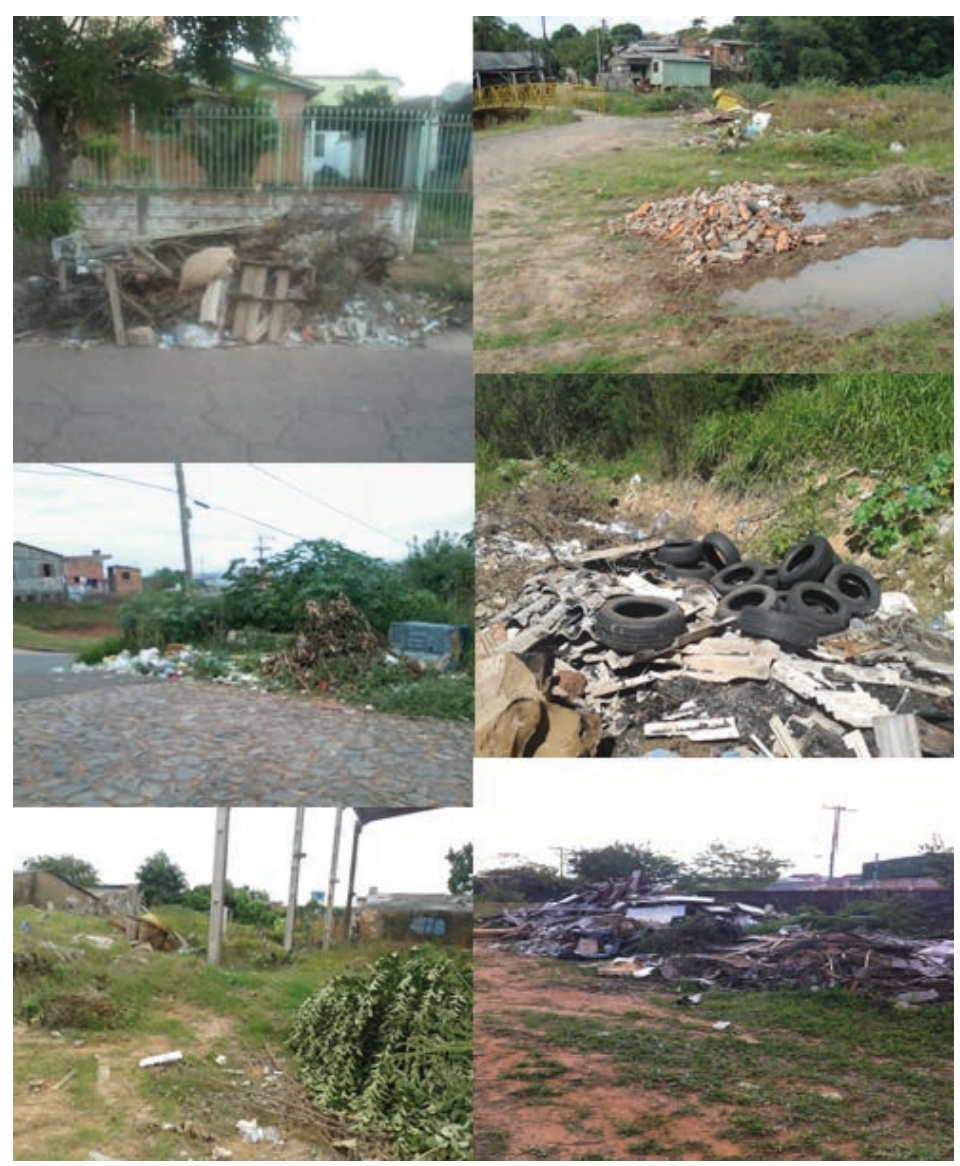

Nota: Imagens em que se observa diversos locais com deposição inadequada de resíduos sólidos de diferentes tipos nas ruas ou em terrenos baldios dos bairros dos estudantes.

Fonte: Arquivo do autor.

A PNRS preconiza a prevenção e a redução da geração de resíduos, recomendando a prática de hábitos de consumo sustentável, além de outras propostas, como o conceito de "logística reversa", segundo a qual o retorno do resíduo gerado ao fabricante visa a diminuir ao máximo os resíduos que terão como destino final os aterros sanitários (BRASIL, 2010). As imagens da Figura 
9 revelam a presença de pneus no ambiente, cujo destino final após sua vida útil está previsto no conceito de logística reversa da PNRS, conforme mencionamos anteriormente. Tais resíduos na cidade de Sapucaia do Sul devem ser encaminhados ao depósito da Secretaria de Obras conforme prevê o Plano Municipal de Gestão Integrada de Resíduos Sólidos.

É importante lembrar que a presença de resíduos sólidos depositados inadequadamente no ambiente atrai animais sinantrópicos, como ratos e baratas. Esta relação confirma os achados já discutidos nas questões 7 e 9 deste estudo, quando os estudantes mencionaram haver a presença destes animais em seus bairros. De acordo com Günther (2005), além dos ratos e das baratas, as moscas e os mosquitos estão entre os principais vetores e/ou reservatórios de diversas doenças que encontram condições adequadas à sobrevivência nos resíduos sólidos urbanos. A autora refere que representam um importante problema sanitário de ordem pública devido à morbidade e à mortalidade que causam.

Segundo Dias (2008), a questão dos resíduos urbanos é um dos grandes problemas das cidades brasileiras, cujo gerenciamento dos sistemas de coleta, tratamento e disposição final, além de dispendioso, tem levado ao insucesso inúmeros esforços na sua resolução. $\mathrm{O}$ excesso de resíduos nos cursos d’água promove seu assoreamento, cujo resultado pode ser percebido nas chuvas intensas, quando não suportam a vazão das águas, extravasam e acabam provocando enchentes. Além disso, causam poluição visual bem como do ar pela liberação de material particulado, de gases e odores oriundos da decomposição biológica, fato que pode ser mais grave quando queimados intencionalmente ao ar livre (GÜNTHER, 2005). Estas considerações permitem comparações com os relatos dos estudantes anteriormente citados quando eles descrevem “...animais mortos...” como tipos de resíduos sólidos liberados no ambiente.

Compreendemos que as ponderações ao longo desta discussão podem ser evidenciadas por meio do pensamento de Teramussi (2008), quando a autora destaca que os estudos de percepção ambiental buscam entender os fatores, os mecanismos e os processos que direcionam as pessoas a terem determinadas ideias e ações em relação ao meio no qual se inserem. 
As diferentes formas de percepção explicitadas pelos estudantes demonstram ter sentido nas concepções de Okamoto (2002), pois segundo este autor nossa mente recebe uma infinidade de estímulos externos, dos quais faz uma seleção dos aspectos de interesse, o que revela sua percepção. O mesmo autor destaca que "[...] o controle da natureza e o controle do comportamento estão mutuamente ligados, assim como a alteração provocada pelo homem sobre a natureza altera a própria natureza do homem" (VYGOTSKY, 1991 apud OKAMOTO, 2002, p. 18). Dessa forma, entende-se que há um processo de interação reflexivo entre indivíduo e natureza, o que induz a pensar que os estudantes, em razão das alterações ambientais que vivenciam, estão sujeitos a comportamentos também distorcidos. Tais fatos podem direcioná-los a condutas degradantes, sem que isso ocorra conscientemente.

Segundo Mellazo (2005), o ser humano e a natureza distanciaram-se ao longo do tempo, resultando em uma relação progressivamente hostil e superficial, perceptível por intermédio das formas de comportamentos sociais, as inversões de valores culturais e ambientais, cujas causas podem ser atribuídas à perversidade do sistema econômico do mundo atual. Torna-se relevante citar Coimbra (2004), cujo discurso menciona que é necessário investir no aprimoramento da percepção das pessoas, tanto individual quanto coletivamente, desenvolvendo a sensibilidade e juízos adequados da realidade ambiental.

Diante do exposto, torna-se importante readquirir e estimular valores positivos, gerando novos sentidos de percepção do ambiente natural de forma que os indivíduos e a coletividade, no caso dos bairros dos estudantes, possam atribuir ao mundo que os rodeia o grau de importância por ele merecido. Nesse contexto, Loureiro (2012) argumenta que a vida não é a expressão direta dos valores éticos, manifestando-se uma complexidade de fatores que concorrem para o modo como agimos, citando que "mente, cérebro e cultura formam uma teia complexa" (LOUREIRO, 2012, p. 57).

Há que se praticar uma EA rumo à construção de uma ética ecológica, considerando os determinantes sociais que abrangem os bairros das comunidades analisadas pelos estudantes, cujas práticas mostram-se degradantes do meio 
ambiente urbano, de forma que percebendo criticamente suas atitudes possam mudar seu comportamento agindo, tal qual preconiza Loureiro (2012), baseados em princípios de responsabilidade com o outro, imprimindo novos rumos a sua relação com a natureza.

\section{Conclusões}

Evidenciou-se ao longo deste estudo que os alunos pesquisados demonstraram ter clareza na percepção da maior parte dos problemas ambientais a sua volta, para os quais foram questionados. Os seus relatos e as imagens fotográficas captadas do ambiente em observação seguramente esclarecem tais aspectos considerados.

A maior parte deles relatou dar importância às discussões sobre as questões ambientais do mundo de hoje juntamente com as declarações de que praticam algumas atitudes pertinentes à preservação ambiental. Além disso, revelaram ter preocupação em relação aos impactos ambientais causados pelos resíduos sólidos dispostos inadequadamente no ambiente, mencionando claramente que decorrem devido a ações humanas indevidas. Neste caso, imputaram às pessoas a responsabilidade pelas mudanças necessárias para a sustentabilidade da Terra.

Diante destes resultados acredita-se que a Educação Ambiental Formal, que é parte do objeto deste estudo, precisa priorizar o investimento em atividades pedagógicas que propiciem aos estudantes em questão o contato efetivo com os temas ambientais que ora vivenciamos. Da mesma forma, estes aspectos mencionados provavelmente poderão contribuir para que os estudantes possam realizar uma análise mais criteriosa da realidade do local em que estão inseridos, e assim, por extensão, visualizar com mais clareza a problemática ambiental da Terra em nossos dias. Isto é um fator imprescindível à formação de seu pensamento crítico e reflexivo, além de favorecer diretamente ações e atitudes ambientalmente positivas, com vistas a contribuir para a sustentabilidade do local em que vivem e consequentemente para o planeta. 


\section{Referências}

ADAMS, B. G. A importância da Lei 9.795/99 e das Diretrizes Curriculares Nacionais da Educação Ambiental para Docentes. Revista Monografias Ambientais - Remoa/UFSM, v. 10, n. 10, out./dez. 2012.

BARBIERI, J. C. Educação ambiental legal: educação ambiental e os problemas ambientais. 2010. Disponível em: <http://portal.mec.gov.br/secad/arquivos/pdf/educacaoambiental/ealegal.pdf>

BARBIERI, J. C.; SILVA, D. Desenvolvimento sustentável e educação ambiental: uma trajetória comum com muitos desafios. Revista de Administração Mackenzie (on-line), São Paulo, v. 12, n. 3, jun. 2011.

BOFF, L. Sustentabilidade: o que é e o que não é. Petrópolis, RJ: Vozes, 2012. 189 p.

BRASIL. Ministério do Meio Ambiente. Lei no 6.938, de 31 de outubro de 1981. Dispõe sobre a Política Nacional do Meio Ambiente, seus fins e mecanismos de formulação e aplicação, e dá outras providências. Brasília, DF.

. Constituição Federal (1988). Constituição da República Federativa do Brasil. Brasília, DF, 1988.

. Lei de Diretrizes e Bases da Educação Nacional (LDB). Lei n. 9.394, de 20 de dezembro de 1996. Estabelece as Diretrizes e Bases da Educação Nacional. Câmara dos Deputados. Série Legislação. Centro de Documentação e Informação. Biblioteca Digital. 8. ed. Brasília, DF, 1996.

. Ministério da Educação; Secretaria de Educação Fundamental. Parâmetros Curriculares Nacionais: introdução aos parâmetros curriculares nacionais. Brasília, DF: MEC; SEF, 1997.

. Parâmetros Curriculares Nacionais: terceiro e quarto ciclos do ensino fundamental: tema transversal meio ambiente. Brasília: MEC; SEF, 1998.

. Lei $n^{\circ}$ 9.795, de 27 de abril de 1999. Dispõe sobre a educação ambiental, institui a Política Nacional de Educação Ambiental e dá outras providências. Brasília, DF, 1999.

. Decreto $n^{\circ} 4.281$, de 25 de junho de 2002. Regulamenta a Lei no 9.795, de 27 de abril de 1999, que institui a Política Nacional de Educação Ambiental, e dá outras providências. Brasília, DF, 2002.

. Ministério do Meio Ambiente; Ministério da Educação. ProNEA: Programa Nacional de Educação Ambiental. 2. ed. Brasília, DF: MMA; MEC, 2005. Disponível em: < http://www.mma.gov.br/publicacoes/educacao-ambiental/ category/98-pronea> Acesso em: 30 maio 2014. 
BRASIL. Legislação. Cidades sustentáveis. Resíduos sólidos. Lei 12.305, de 2 de agosto de 2010. Institui a Política Nacional de Resíduos Sólidos. Brasília, DF, 2010.

BRASIL. Ministério da Educação; Conselho Nacional de Educação, Conselho Pleno. Resolução nº 2, de 15 de junho de 2012. Estabelece as Diretrizes Curriculares para a Educação Ambiental. Brasília, DF, 2012.

. Educação ambiental por um Brasil sustentável: ProNEA, Marcos Legais e Normativos. DEA; SAIC. 4. ed. Brasília, DF: MMA; MEC, 2014.

CARVALHO, I. C. M. Educação ambiental: a formação do sujeito ecológico. São Paulo, SP: Cortez, 2008.

COIMBRA, J. A. A. Linguagem e percepção ambiental. In: PHILIPPI JÚNIOR, A.; ROMÉRO, M. de A.; BRUNA, G. C. Curso de gestão ambiental. Barueri, SP: Manole, 2004. p. 525-547.

DIAS, G. F. Educação ambiental: princípios e práticas. 7. ed. São Paulo, SP: Gaia, 2008. 551 p.

. Ecopercepção: um resumo didático dos desafios socioambientais. São Paulo, SP: Gaia, 2004. 61 p.

DÍAZ, A. P. Educação ambiental como projeto. 2. ed. Porto Alegre, RS: Artmed, 2002.

FIGUEIREDO, L. V. R. Percepção ambiental em uma unidade de conservação de proteção integral. 2011. Dissertação (Mestrado) - Universidade Estadual de Montes Claros, MG, Montes Claros: UEMC, 2011.

FUCHS, R. B. H. Educação ambiental como desenvolvimento de atividades interdisciplinares na $5^{a}$ série do Ensino Fundamental. 2008. Monografia (Especialização) - USM, Santa Maria, RS, 2008.

GIL, A. C. Como elaborar projetos de pesquisa. São Paulo. SP: Atlas, 2002.

GONÇALVES, F. S. A expansão urbana sobre o relevo do município de Sapucaia do Sul-RS. 2013. Dissertação (Mestrado) - Universidade Federal do Rio Grande do Sul, UFRGS, Porto Alegre, 2013.

GÜNTHER, W. M. R. Poluição do solo. In: PHILIPPI JR., A.; PELICIONI, M. C. F. (Eds.). Educação ambiental e sustentabilidade. Barueri, SP: Manole, 2005.

JACOBI, P. Educação ambiental, cidadania e sustentabilidade. Cad. Pesqui., São Paulo, n. 118, mar. 2003.

. Educação e meio ambiente - transformando as práticas. Revista brasileira de educação ambiental - REVBEA, Brasília, n. 0, p. 28-35, 2004.

. Educação ambiental: o desafio da construção de um pensamento crítico, complexo e reflexivo. Educ. Pesqui., São Paulo, v. 31, n. 2, ago. 2005. 
LEFF, Henrique. Saber ambiental: sustentabilidade, racionalidade, complexidade, poder. Petrópolis, RJ: Vozes, 2004.

LEFF, Henrique. Epistemologia ambiental. 3. ed. São Paulo, SP: Cortez, 2006.

LIMA, G. C. O discurso da sustentabilidade e suas implicações para a educação. Ambient. Soc., Campinas, v. 6, n. 2, dez. 2003.

LOUREIRO, C. F. B. Trajetória e fundamentos da educação ambiental. 4. ed. São Paulo, SP: Cortez, 2012.

MELLAZO, G. C. Percepção ambiental e educação ambiental: uma reflexão sobre as relações interpessoais e ambientais no espaço urbano. Olhares \& Trilhas, Uberlândia, n. 6, p. $45-51,2005$.

MINAYO, M. C. S.; GOMES, S. F. D. R. Pesquisa social: teoria, método e criatividade. Petrópolis, RJ: Vozes, 2013.

MORESI, E. (Org.). Metodologia de pesquisa. 2003. Dissertação (Mestrado em Gestão do Conhecimento e Tecnologia de Informação) - Universidade Católica de Brasília. Brasília: UCB, 2003.

NAIME, R.; GARCIA, A. C. A. Percepção ambiental e diretrizes para compreender a questão do meio ambiente. Novo Hamburgo, RS: Feevale, 2004.

OKAMOTO, J. Percepção ambiental e comportamento: visão holística da percepção ambiental na arquitetura e na comunicação. São Paulo: Mackenzie, 2002.

PELICIONI, A.F. Movimento ambientalista e educação ambiental. In: PHILIPPI JUNIOR, A.; PELICIONI, M. C. F. (Eds.). Educação ambiental e sustentabilidade. Barueri, SP: Manole, 2005.

SAPUCAIA DO SUL. Secretaria do Meio Ambiente. Cronograma de coleta de lixo domiciliar. Rotas de coleta domiciliar. Sapucaia do Sul: Prefeitura. 2014.

SAUVÉ, L. Educação ambiental e desenvolvimento sustentável: uma análise complexa. Revista de Educação Pública, 1997. Disponível em: <www.serrano.neves.nom.br/ MBA_GYN/edsoc10.pdf>.

SILVEIRA, C. M. V. Proposta de um horto medicinal na Escola Estadual de Ensino Médio Vila Prado a partir do resgate etnobotânico das plantas medicinais na Comunidade escolar. 2005. 88 f. Trabalho de Conclusão de Curso (Graduação) - Universidade do Vale do Rio dos Sinos, Unisinos, São Leopoldo, RS, 2005.

SORRENTINO, M. et al. Educação ambiental como política pública. Educ. Pesqui., São Paulo, v. 31, n. 2, ago. 2005.

TERAMUSSI, T. M. Percepção ambiental de estudantes sobre o Parque Ecológico do Tietê, São Paulo - SP. 2008. Dissertação (Mestrado) - Universidade de São Paulo, USO, São Paulo, SP, 2008. 